\title{
PERANCANGAN SISTEM MONITORING DAN KONTROLING PENGGUNAAN DAYA LISTRIK BERBASIS ANDROID
}

\author{
Ikwan'), Yan Mitha Djaksana ${ }^{2}$ ) \\ ${ }^{1,2}$ STMIK Eresha J1. Raya Puspiptek, Buaran, Kec. Serpong, \\ Kota Tangerang Selatan, Banten 15310 (021) 74709855 \\ e-mail :ikwanali020@gmail.com 1), dosen40079@eresha.ac.id ${ }^{2)}$ \\ * Korespondensi: e-mail: ikwanali020@gmail.com
}

\begin{abstract}
ABSTRAK
IoT (Internet Of Things) sudah menjadi konsep teknologi yang semakin lama semakin banyak digunakan. Baik untuk keperluan industri maupun komersil. Dengan hadirnya IoT (Internet Of Things) dapat menjadikan beberapa komponen elektronika seperti media sensor dan media penggerak seperti servo motor serta perangkat lainnya bisa di kontrol secara otomatis selama alat tersebut terhubung ke internet. Dalam penelitian ini penulis memaparkan mengenai perancangan sistem kontrolingdan monitoring penggunaan daya listrikdengan aplikasi android berbasis IoT dengan menggunakan modul NodeMCU ESP8266 V3, Relay 4 Channel dan modul PZEM004T sebagai alat untuk membaca arus listrik. Alat ini akan membantu pemilik rumah dalam mengontrol dan memonitor penggunaan daya listrik secara jarak jauh dan secara real time.
\end{abstract}

Kata Kunci:Internet Of Things,NodeMCU ESP8266, Relay 4 Channel, WiFi,PZEM-004T

\section{ABSTRACT}

IoT (Internet Of Things) has become a technology concept that is increasingly being used. Both for industrial and commercial purposes. With the presence of the IoT (Internet Of Things), it can make several electronic components such as sensor media and driving media such as servo motors and other devices that can be controlled automatically as long as the tool is connected to the internet. In this study, the authors describe the design of a control system and monitoring of electric power usage with an IoT-based android application using the ESP8266 V3 NodeMCU module, 4 Channel Relay and the PZEM-004T module as a tool for reading electric currents. This tool will assist home owners in controlling and monitoring the use of electric power remotely and in real time.

Keywords: Internet Of Things, NodeMCU ESP8266, Relay 4 Channel, WiFi, PZEM-004T 


\section{PENDAHULUAN}

Berdasarkan laporan dari Badan Perindustrian dan Energi Provinsi DKI Jakarta, yang memiliki pengguna listrik pada sektor rumah tangga dengan total 4220,18 pelanggan pada tahun 2019. Dimana mayoritas pelanggannya masih menggunakan jenis meteran listrik manual atau analog dengan sistem pembayaran bulanan atau pascabayar.Dimana pelanggannya rata-rata tidak mengetahui jumlah pemakaian listriknya selama pemakaian di bulan berjalan. Dan hanya akan tahu pada saat tagihan listrik bulanan sudah terbit atau dikeluarkan oleh pihak PLN [1]. Berbeda dengan pelanggan yang menggunakan listrik dengan meteran KWh digital berjenis prabayar, dimana mereka bisa mengontrol penggunaan daya listrik mereka, karena mereka sendiri yang menentukan besaran daya listrik yang akan mereka gunakan dengan cara melakukan isi ulang menggunakan kode khusus yang banyak dijual di konter pulsa atau sejenisnya. Dengan begitu mereka bisa memperkirakan berapa biaya yang akan mereka keluarkan untuk penggunaan listriknya [2].Berangkat dari hal tersebut maka dilakukan sebuah penelitian dengan mengangkat judul penelitian "Perancangan Sistem Monitoring dan Kontroling Penggunaan Daya Listrik Berbasis Android", dengan menggunakan microcontrollerNodeMCU ESP8266 V3 yang sudah terintegrasi Wi-Fi, Relay4 Channel5V DC, dan modul pembaca arus listrik PZEM 004T.Diharapkan dari penelitian ini bisa bermanfaat dalam mengontrol peralatan listrik rumah secara jarak jauh dan juga proses monitoring penggunaan daya listrik sehingga bisa mengetahui estimasi atau prakiraan tagihan listrik yang akan datang yang dapat dilihat dari aplikasi android. Selama peralatan elektronik yang digunakan di rumah tersebut terhubung ke alat, begitu juga alatnya dalam kondisi baik dan terhubung dengan jaringan internet [3] [4] [5].

\section{LANDASAN TEORI}

\subsection{Pengertian Realtime Database}

Realtime database adalah database NoSQLdariFirebase, dengan kata lain database yang tidak menggunakan relasi data seperti pada $M y S Q L$ dan sejenisnya.Di mana metode penyimpanan data $N o S Q L$ di simpan dalam format JSON (JavaScript Object Notation) dan host pada cloud dan bisa melakukan update data baru secara otomatis dan bisa digunakan bebagai platform sistem operasi handphone seperti android dan iOS [6] [7].

\subsection{Pengertian Telegram Bot}

Telegram bot merupakan sebuah akun bot atau robot dari aplikasi pesan telegram yang dapat diprogram dengan berbagai perintah untuk menerima dan memberikan respon dari perintah tersebut, sehingga dapat menjalankan perintah atau intruksi yang di kirimkan penggunanya dari bot telegram. Cara membuat akun bot telegram yaitu melalui bot master yang memiliki nama akun telegram @BotFather di mana akun tersebut sudah disediakan oleh telegram [8] [9].

\subsection{NodeMCU ESP8266 V3}

NodeMCU ESP8266 adalah pengembangan dari ESP 8266 yang diberikan board yang dilengkapi portmicro usb sehingga dapat memasukan program ke dalamnya dan bisa digunakan sebagai microcontroller tanpa harus 
terhubung ke Arduino. NodeMCU ESP8266 menggunakan Bahasa pemrograman Lua, di mana tools yang digunakan yaitu LuaLoader atau LuaUploader[10][11].

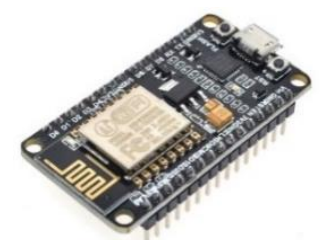

Gambar 2.7 NodeMCU ESP8266 V3

\subsection{Relay4 Channel}

Secara prinsip kerjanya relay tergolong ke dalam jenis saklar (switch), di mana relay berfungsi sebagai penghubung dan pemutus arus listrik yang kendalikan oleh sebuah pemicu atau sinyal picu dari perangkat elektronik lain yang terhubung dengannya. Secara umum terdapat dua jenis relay, yaitu relay mekanis dan Solid State Relay (SSR) [12].

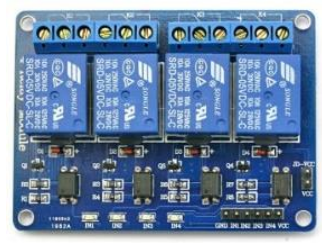

Gambar 2.9 Relay 4 Channel

\subsection{PZEM-OO4TV3.0}

PZEM-004T V3.0 merupakan sebuah modul elektronik yang diproduksi sebuah perusahaan bernama Peacfair. Di mana modul ini memiliki fungsi sebagai pengukur tegangan listrik (voltage), arus listrik (current), daya (power) dan power factor. Versi 3 ini merupakan pergantian dari V2.0, di mana pada pada versi 3 ini memiliki kelebihan pembacaan data dari sensor pembaca arus CloseCurrent Transformer atau Close (CT) yang lebih cepat [13] [14].

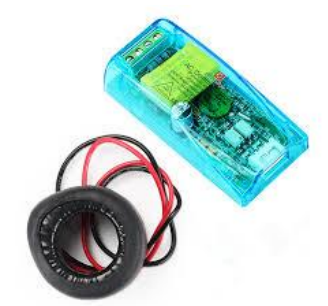

Gambar 2.10 Modul PZEM-004T V3.0 
JURSISTEKNI (Jurnal Sistem Informasi dan Teknologi Informasi) Vol 2, No.3, September 2020: Hal 13 - 24

ISSN. P: 2715-1875, E: 2715-1883

\section{ANALISA DAN PERANCANGAN}

\subsection{Analisa}

Pada tahap ini, dilakukan analisa kebutuhan sistem, yang dibagi ke dalam tiga bagian, yaitu diantaranya analisa kebutuhan input, proses dan output. Seperti di tunjukan pada gambar 3.1.

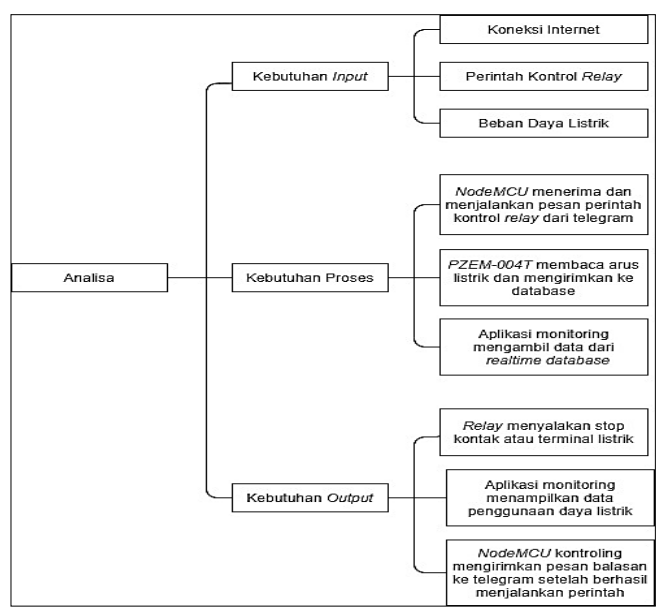

\subsection{Perancangan}

Gambar 3.1 Bagan Analisa Kebutuhan Sistem

Perancangan dalam penelitian ini dibagi menjadi 2 bagian, yaitu meliputi perancangan perancanganperangkat keras (hardware) dan perangkat lunak (software).

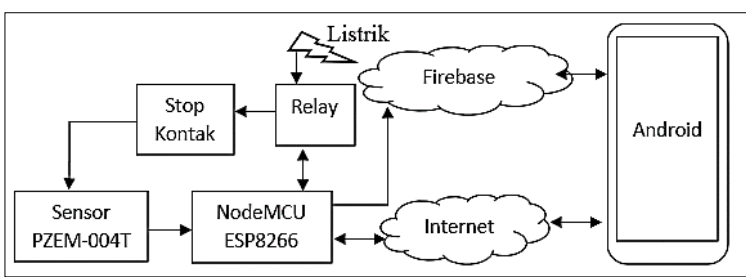

Gambar 3.2 Desain Keseluruhan Sistem

Dari gambar blok diagram 3.2, maka dapat digambarkan activity diagram sistem secara keseluruhan seperti pada gambar 3.3, beserta use case dari penggunaan sistem tersebut seperti di tunjukan pada gambar 3.4.

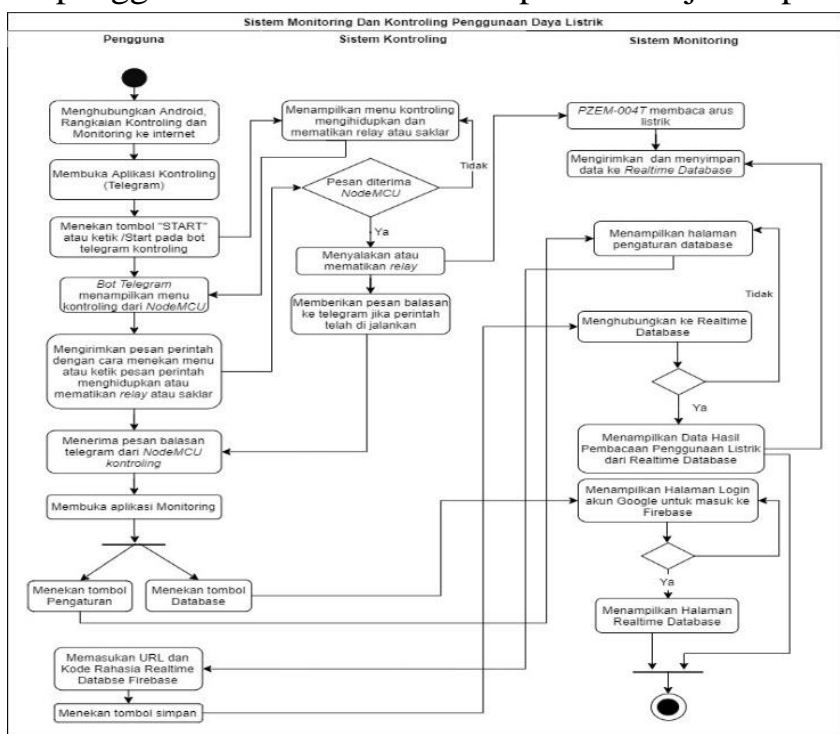

Gambar 3.3 Activity Diagram Keseluruhan Sistem 


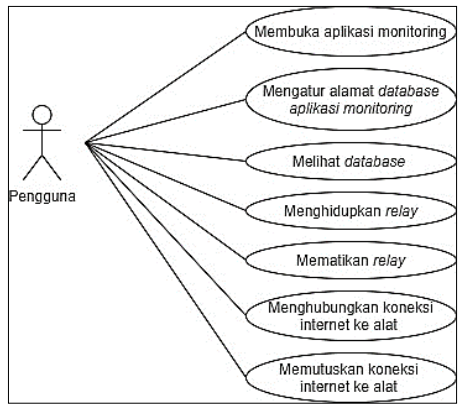

Gambar 3.4 Use Case Sistem Monitoring Dan Kontroling

\subsubsection{Perancangan Perangkat Keras (Hardware)}

Pada perancangan perangkat keras ini dilakukan perancangan komponen sistem kontroling dan monitoring yang terdiri dari modul NodeMCU ESP8266, Relay 4 Channel, PZEM-004T dan stop kontak yang berfungsi untuk memasukan beban penggunaan daya listrik. Rancangan perangkat keras ini berfungsi sebagai kontrol untuk menghidupkan dan mematikan arus listrik pada stop kontak yang ada pada rancangan alat ini sekaligus monitoring penggunaan daya listrik dari beban yang terpasang pada alat.Dengan menggunakan aplikasi pesan telegram sebagai media pengirim perintah ke NodeMCU ESP8266 yang kemudian akan diteruskan ke relay, serta tambahan aplikasi android yang berfungsi untuk monitoring penggunaan daya listrik. Di mana data yang ditampilkan pada aplikasi diperoleh dari realtime database. Adapun gambar rangkaian dari alat atau prototype seperti pada gambar 3.5.

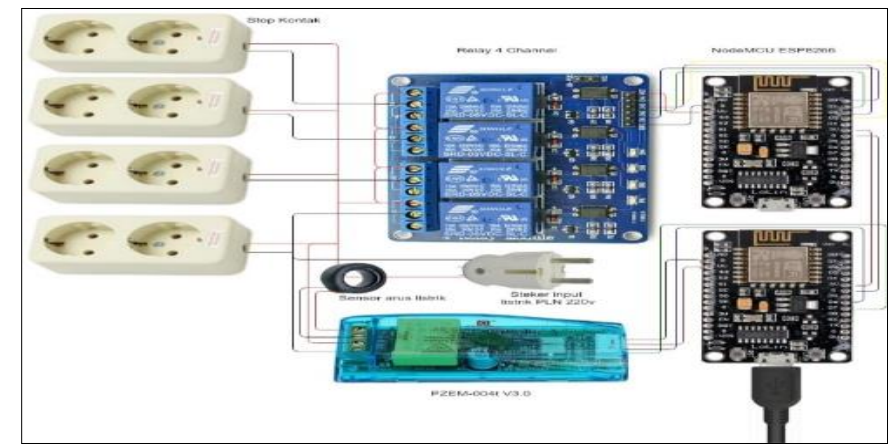

Gambar 3.5 Perancangan Perangkat Keras

Kedua NodeMCU ESP8266 tersebut menggunakan sumber daya yang sama dalam satu rangkaian. Yaitu dengan menambahkan baseboard atau papan induk yang sesuai atau sama dengan tipe NodeMCU yang dipakai yaitu NodeMCU ESP8266 V3.

Dengan menggunakan baseboard tersebut, penggunaan daya dua buah NodeMCU ESP8266 V3 dapat didigabungkan tanpa harus merubah atau menambahkan kabel tambahan pada NodeMCU secara langsung karena PIN header yang ada pada NodeMCU menjadi banyak dengan dipasangkan pada baseboard. Cukup dengan satu adaptor dengan kapasitas daya maksimal $12 \mathrm{~V}$ DC $2 \mathrm{~A}$ maka kedua NodeMCU tersebut bisa menyala dan menjalankan tugasnya masing-masing tanpa saling mempengaruhi kinerjanya. Sehingga hasilnya akan seperti pada gambar $3.6[15]$. 
JURSISTEKNI (Jurnal Sistem Informasi dan Teknologi Informasi) Vol 2, No.3, September 2020: Hal 13 - 24

ISSN. P: 2715-1875, E: 2715-1883

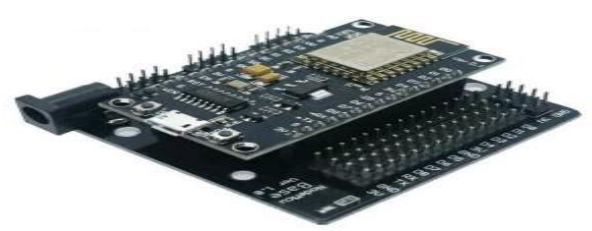

Gambar 3.6 NodeMCU ESP8266 V3 dengan Baseboard

Berikut ini merupakan tabel skematik dari rancangan komponen dan modul dalam pembuatan prototype dalam penelitian ini.

Tabel 3.1 Skematik PIN Relay 4 Channel dengan NodeMCU ESP8266

\begin{tabular}{cc}
\hline PZEM-004T V3.0, \\
Relay 4 Channel dan \\
NodeMCU ESP8266 V3 & NodeMCU ESP8266 V3 \\
\hline 3V NodeMCU & $3 V$ \\
GND Relay, PZEM, NodeMCU & $G N D$ \\
IN1 Relay & $G P I O 16$ / Do \\
IN2 Relay & $G P I O 5 / D 1$ \\
IN3 Relay & $G P I O 4$ / D2 \\
IN4 Relay & $G P I O 2 / D 3$ \\
TX PZEM & $G P I O 12$ / D6 \\
RX PZEM & $G P I O 13$ / D7
\end{tabular}

\subsubsection{Perancangan Perangkat Lunak (Software)}

Pada perancangan perangkat lunak ini dibagi menjadi dua bagian, yaitu perancangan chat bot telegram sebagai kontroling alat dan perancangan aplikasi monitoring penggunaan daya listrik.

\subsubsection{Perancangan Program SistemKontroling}

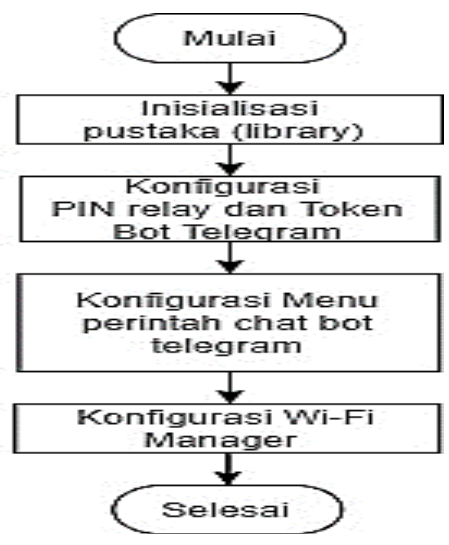

Gambar 3.7 Flowchart Program Kontroling 


\subsubsection{Perancangan Chat Bot Telegram}

Pada proses pembuatan chat bot telegram tersebut, kita akan diberikan nomor API Token, yang nantinya untuk digunakan sebagai penghubung antara telegram dan NodeMCU ESP8266.

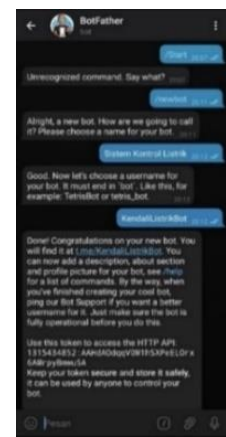

Gambar 3.14 Proses Pembuatan Chat Bot Telegram

Setelah itu baru lakukan uji coba chat bot telegram dengan cara menekan teks t.me/KendaliListrikBot pada pesan yang dikirimkan oleh @ BotFather. Maka seharusnya akan diarahkan ke chat bot telegram yang telah dibuat.

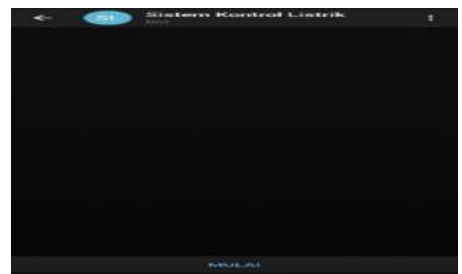

Gambar 3.15 User Interface Chat Bot Telegram

Setelah halaman chat bot telegram sistem kontroling yang telah dibuat terbuka, maka untuk menampilkan menu perintahnya yaitu dengan cara menekan tombol "MULAI" atau "START". Sebelumnya pastikan rangkaian pusat kontrol NodeMcu dengan Relay dihubungkan dengan jaringan internet melalui Wi-Fi Manager yang telah diprogram pada NodeMCU.

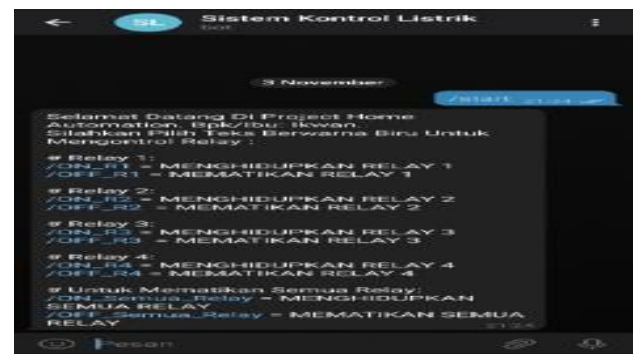

Gambar 3.16 Tampilan Menu Chat Bot Telegram

Adapun cara kerja dari chat bot telegram ini seperti digambarkan dalam flowchart berikut ini. 
JURSISTEKNI (Jurnal Sistem Informasi dan Teknologi Informasi) Vol 2, No.3, September 2020: Hal 13 - 24

ISSN. P: 2715-1875, E: 2715-1883

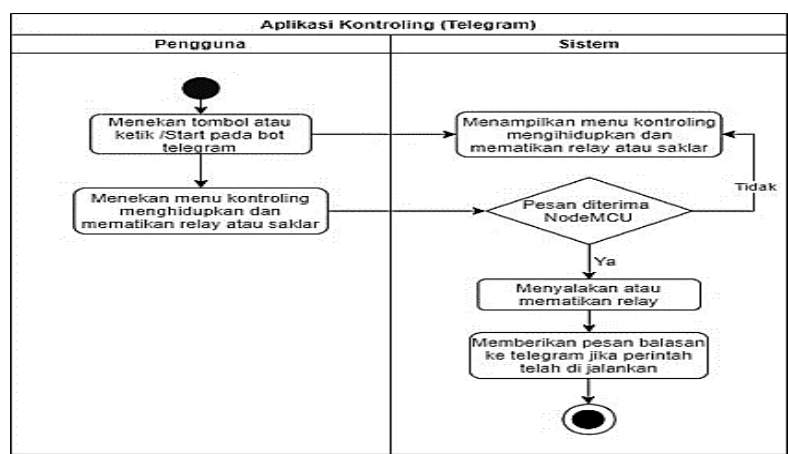

Gambar 3.17 Activity DiagramChat Bot Telegram

\subsubsection{Perancangan Program Sistem Monitoring}

BerikutinimerupakanFlowchart dariprogram monitoring

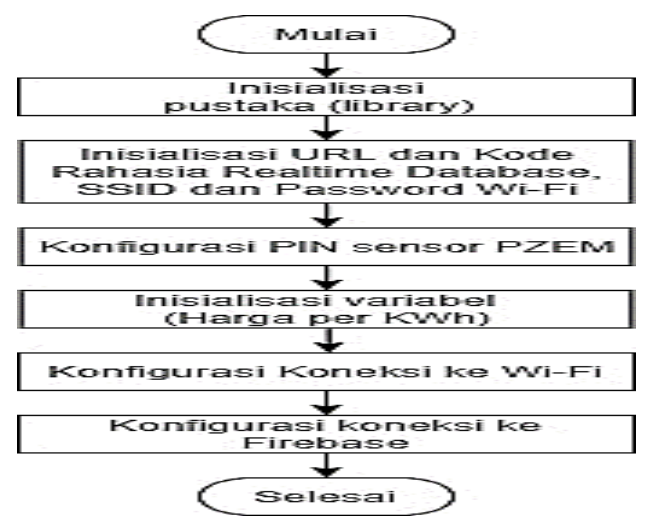

Gambar 3.32 Flowchart Program Monitoring

Berikut ini activity diagram dari aplikasi monitoring.

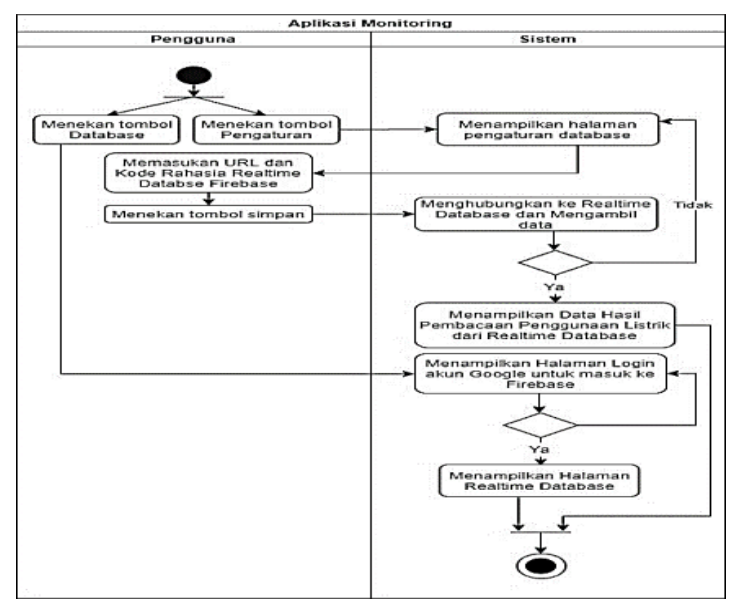

Gambar 3.18 Activity Diagram Aplikasi Monitoring 
JURSISTEKNI (Jurnal Sistem Informasi dan Teknologi Informasi) Vol 2, No.3, September 2020: Hal 13 - 24

ISSN. P: 2715-1875, E: 2715-1883

\subsection{Implementasi Prototype}

\section{IMPLEMENTASI DAN PENGUJIAN}

Berikut ini beberapa gambar yang diambil pada saat proses implementasi alat atau prototype:

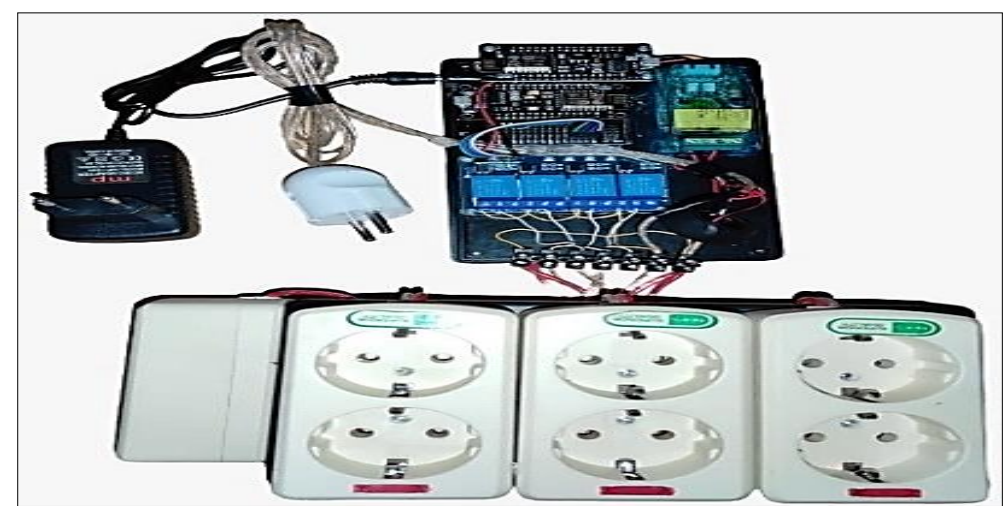

Gambar 4.1 Implementasi Rangkaian Prototype

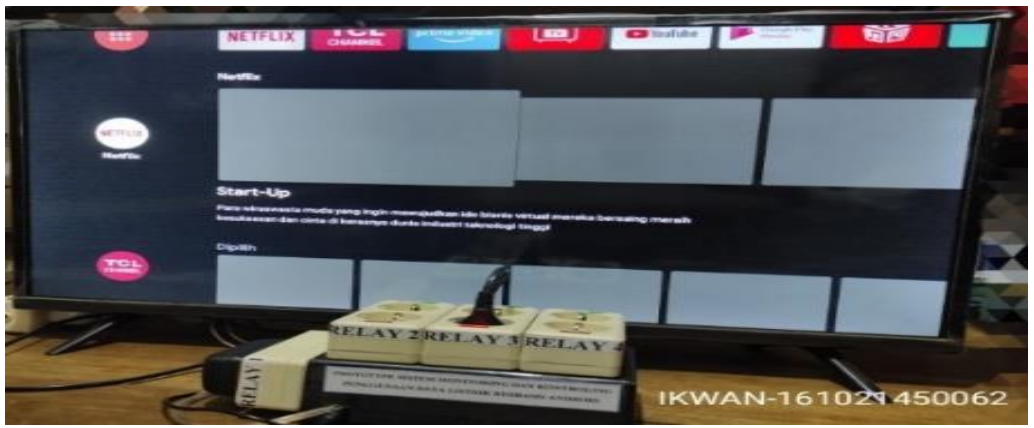

Gambar 4.2 Implemetasi Prototype Pada LED TV

\subsubsection{ImplementasiChat Bot Telegram}

Berikut ini tampilan dari user interface chat bot telegram yang digunakan untuk mengontrol penggunaan listrik pada prototype.

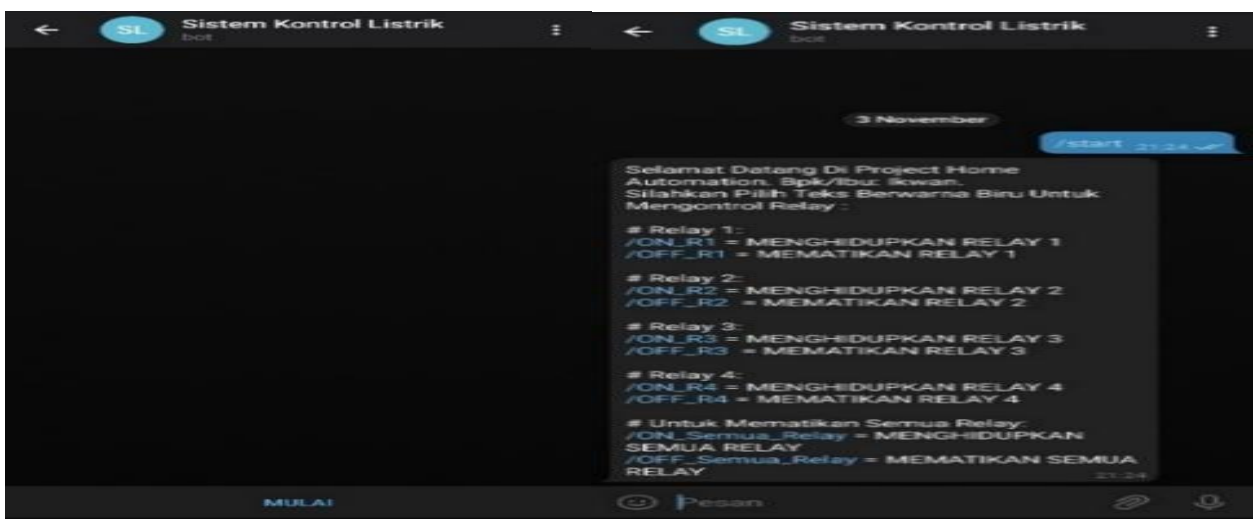

Gambar 4.12 User Interface Chat Bot Telegram 


\subsubsection{ImplementasiAplikasi Monitoring}

Berikut ini tampilan dari user interface aplikasi montoring penggunaan listrik pada prototype yang dihasilkan dari pembacaan modul PZEM-004T.

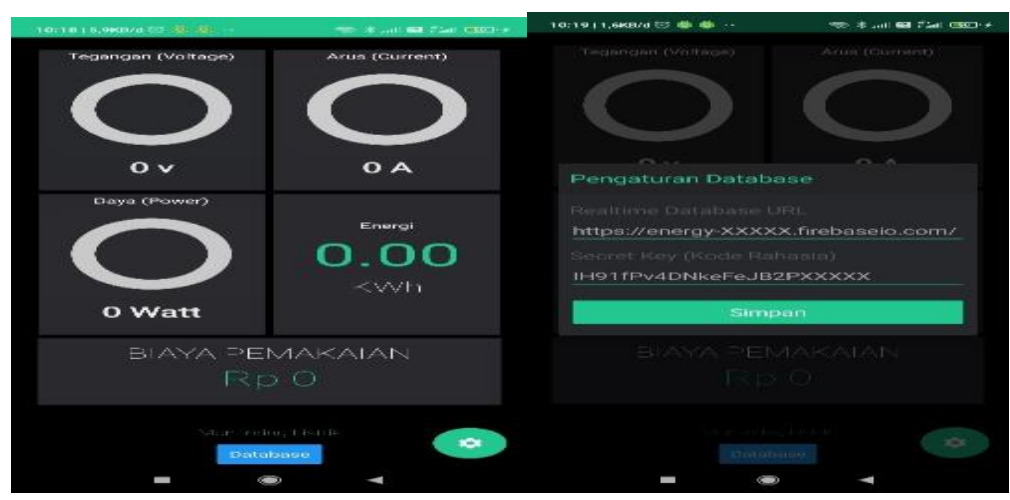

Gambar 4.13 User Interface Aplikasi Monitoring

\subsection{Pengujian Sistem}

Pengujian sistem merupakan tahap dimana sebuah aplikasi atau alat yang telah selesai dirancang akan dilakukan pengujian, baik secara fungsi atau pun programnya. Pada pengujian ini menggunakan metode black box testing, yaitu sebuah metode pengujian fungsional. Dengan kata lain pengujian ini tidak melibatkan struktur program yang ada pada aplikasi atau pun alat.

Tabel 4.4Hasil MonitoringDayaListrikDenganPZEM-004T

\begin{tabular}{|c|c|c|c|c|}
\hline \multirow{2}{*}{ No. } & \multirow{2}{*}{ Jenis Beban } & \multicolumn{3}{|c|}{ Hasil Pengukuran Sensor PZEM-004T } \\
\cline { 3 - 5 } & & $\begin{array}{c}\text { Tegangan } \\
\text { Volt }(\boldsymbol{V})\end{array}$ & $\begin{array}{c}\text { Arus } \\
\text { Ampere }(\boldsymbol{A})\end{array}$ & $\begin{array}{c}\text { Daya } \\
(\boldsymbol{W a t t})\end{array}$ \\
\hline 1 & LED TV & 220.3 & 0.12 & 13.7 \\
\hline 2 & Setrika & 218.7 & 1.59 & 347.4 \\
\hline 3 & Mesin Laminating & 214.9 & 2.81 & 604.5 \\
\hline 4 & Printer & 222.8 & 0.04 & 4.8 \\
\hline 5 & Speaker & 222.8 & 0.03 & 4 \\
\hline
\end{tabular}




\section{KESIMPULAN DAN SARAN}

\subsection{Kesimpulan}

Berdasarkan hasil dari penelitian dan penjelasan yang telah sampaikan pada bab-bab sebelumnya, maka dapat disimpulkan bahwa:

1. Perancangan dari alat atau prototype sistem kontroling dan monitoring penggunaan daya listrik pada penelitian ini dengan menggunakan mikrokontroler NodeMCU ESP8266 dengan cara membuat rangkaian dari menggunakan modul tambahan selain NodeM CU ESP8266. Yaitu Relay 4 Channel sebagai kontroler dan sensor PZEM-004T untuk mengukur daya listrik dan memonitoringnya daria plikasi yang terpasang pada handphone android.

2. Telegram dapat terhubung dan berkomunikasi dengan alat atau prototype dengan menggunakan perantara API Token Telegram yang di masukan kedalam program Node MCU ESP8266. Dengan menggunakan layanan chat bot telegram sebagai pengirim perintah dan penerima balasan dari perintah yang dikirimkan.

3. Pada perancangan sistem monitoring, menggunakan aplikasi android sebagai user interface untuk memonitoring penggunaan daya listrik yang dikirimkan oleh realtime database dari firebase menggunakan $U R L$ dan kode rahasia (secret key) yang telah dikonfigurasikan pada aplikasi android. Data yang ditampilkan aplikasi dan tersimpan di realtime database berasal oleh pembaca sensor PZEM-004T yang terpasang pada rangkaian protoype.

\subsection{Saran}

Dalam penelitian dan pembuatan alat atau prototype ini masih jauh dari kata sempurna. Agar dapat memaksimalkan manfaat dari alat ini, maka penulis menyarankan:

1. Rangkaian alatk hususnya bagian kelistrikan, dirancang dengan baik, agar lebih aman pada saat digunakan dan menggunakan peralatan dan perlengkapan yang menjamin keamanan dan keselamatan.

2. Pada aplikasi monitoring alangkah baiknya jika bisa ditambahkan menu print atau download data histori penggunaan daya listrik secara berkala.

3. Pada sistem kontroling yaitu telegram jika memungkinkan untuk dibuatkan tampilan menu lebih interaktif atau user friendly. Bahkan jika memungkinkan bisa menggunkan aplikasi online messenger lainnya yang lebih umum dan banyak digunakan.

4. Pada aplikasi kontroling (telegram) diharapkan bisa menggunakan ID khusus pemilik dari alat, agar tidak sembarang orang bisa mengontrol alat tersebut. 


\section{DAFTAR PUSTAKA}

[1] Purnama, K., \& Rahajoeningroem, T. Design of Prepaid kWh-Meter Prototype Monitoring Based on Short Message Service (SMS).

[2] Prayogo, S. (2019). Analisis Kualitas Pelayanan Terhadap Kepuasan Pelanggan Pengguna Kwh-Meter Prabayar Perusahaan Listrik Negara Upj Kota Magelang.

[3] Furqon, A., Prasetijo, A. B., \& Widianto, E. D. (2019).Rancang Bangun Sistem Monitoring dan Kendali Daya Listrik pada Rumah Kos Menggunakan NodeMCU dan Firebase Berbasis Android. Techné: Jurnal Ilmiah Elektroteknika, 18(02), 93-104.

[4] Purnomo, T. (2019). Rancang Bangun Sistem Pemantauan Energi Dan Pengendalian Besaran Listrik Berbasis Internet Of Things (Iot) Menggunakan Piranti Nodemcu Dan Pzem-004T (Doctoral dissertation, University of Technology Yogyakarta).

[5] Rizal Mawali, A. C. H. M. A. D., \& Aribowo, W. (2019).Rancang Bangun Pemantauan Pembayaran Dan Konsumsi Listrik Jarak Jauh Berbasis Arduino Uno R3 Dan Modul Bluetooth. Jurnal Teknik Elektro, 9(2)

[6] Arrafi Sasongko, I. (2017). E-Konsultasi Dengan Teknologi Firebase (Studi Kasus Teknik Informatika Universitas Pembangunan Nasional "Veteran" Yogyakarta)(Doctoral Dissertation, Upn" Veteran" Yogyakarta).

[7] Buru, D. (2017). Aplikasi Pendeteksi Lokasi Perangkat Bergerak Menggunakan Teknologi Cloud Computing Dengan Firebase Realtime Database Berbasis Android (Doctoral Dissertation, Stmik Akakom Yogyakarta).

[8] Cokrojoyo, A., Andjarwirawan, J., \& Noertjahyana, A. (2017). Pembuatan Bot Telegram Untuk Mengambil Informasi dan Jadwal Film Menggunakan PHP. Jurnal Infra, 5(1), 224-227.

[9] Gemilang, P. (2020). Purwa Rupa Sistem Pengangkat Sampah Pada Pintu Bendungan Berbasis Internet Of Things (Doctoral Dissertation, Stmik Akakom Yogyakarta).

[10] Efendi, M. Y. (2019). Implementasi Internet of Things Pada Sistem Kendali Lampu Rumah Menggunakan Telegram Messenger Bot Dan Nodemcu Esp 8266. Global Journal of Computer Science and Technology.

[11] Alipudin, A. M. (2018). Rancang Bangun Alat Monitoring Biaya Listrik Terpakai Berbasis Internet Of Things (Iot). Jurnal Online Mahasiswa (JOM) Bidang Teknik Elektro, 1(1).

[12] Efendi, M. Y. (2019). Implementasi Internet of Things Pada Sistem Kendali Lampu Rumah Menggunakan Telegram Messenger Bot Dan Nodemcu Esp 8266. Global Journal of Computer Science and Technology.

[13] Habibi, F. N., Setiawidayat, S., \& Mukhsim, M. (2017, October). Alat Monitoring Pemakaian Energi Listrik Berbasis Android Menggunakan Modul PZEM-004T. In Prosiding Seminar Nasional Teknologi Elektro Terapan (Vol. 1, No. 01, pp. 157-162). 